\title{
Development Model and Personality Study of Immigrant Villages_—Bin Ya
}

\author{
Xiaomei Chen \\ Qiongtai Teachers College, Art College, Haikou, Hainan, 571127 \\ Email: 39858545@qq.com
}

Keywords: Island Village; Bin Ya Village; Immigrants

\begin{abstract}
Due to its geography, history and development, the development of islands lags behind. Bin Ya village is a typical immigrant village in Haikou City, Hainan Province. Based on the investigation and study of the village, it is learned that the village was reclaimed in the Yuan Dynasty and investigated for the development of the coastal villages. Systematic arrangement of the emergence and development of villages not only obtains a valuable research result but also vividly presents the cultural identity of island villages and obtains the knowledge of the development of island villages.
\end{abstract}

\section{Introduction}

Hainan Island culture is a flexible and elastic concept of geo-culture, with a variety of interpretation methods. The so-called geography, in addition to the division of natural geography and the distribution of natural ecology is the determining factor, the specific regional folk culture is not negligible factors, and these two are often dialectical unity. The village is the basic unit of island society construction, and the word "village" is called "village" in "Chinese Folklore" in Utopian. Island research starts from the village and is an effective way to examine the geo-culture through folk memory. However, based on historical reasons, the historical records of Hainan village are relatively scarce. To study the native society, we must rely on a great deal of legends, myths and other verbal "history." Contemporary social psychologists interpret the social nature of the formation and maintenance of this memory and affirm the inheritance and continuity of this memory. Therefore, it is an effective way to use the folklore and folk tales to track the historical development of regional development.

Through field investigation and interviews, I collected the local memory and the genealogy of the family to organize the folk memory of Bin Ya Village in Haikou City, Hainan Province. I explained the reasons for the formation of Bin Ya Village and explored the mode of the development of the villages of immigrants in Hainan Province. - rural edge, to analyze the customs of its cultural identity issues for its future development of related issues, aimed at the present stage of the development of traditional villages to provide some reference and reference.

\section{The Geography and History}

Bin Ya village is located in the western suburbs of Haikou, Hainan Province, east longitude 110.1743, latitude 20.015, east of Binlian village, west of Shuchang village, and south of Shuitou and Xin village, north to Qiongzhou Strait. Because of its coast by the sea, it is named "Bin Ya ", it's a typical immigrant village.

Originally, name of Bin Ya had not pass through, it was built with the changging of coastline and the formation of immigrants in the settlement of the village. The Han and Tang dynasties Haikou ancient map no Bin Ya Village can test, "Wanli Qiongzhou Fu Chi" first mentioned it, "Wulong pool: West County, distant about twelve li, where there is Wuyuan Du, Five spring there, water into a pool, through Bin Ya and Nan Mao into the sea "[2]," Tomb of Hai Rui, official of You Du Yu who was conferred as loyal: in Bin Ya"[3]. According to the Qiongshan county map (see Figure 1) provided by Zhengde Qiongtai Chi, one of the most complete and earliest record of Hainan Province, and the "Wulong Xizhu" Figure of Haikou provided by Hongyuan Long today [4], We can see that before 
the Song Dynasty, "Bin Ya Village," the place where the wasteland and beach. As the changes of time, the Nandu River alluvial sediment increasingly accumulated, "Nandu River estuary appeared a piece of beach, it was called the 'Haikou Pu', this was the formation of Haikou"[5]. Haikou, coastal terrain around the continuous change, year by year, one by one, according to the beach is forming a village, the geography is the primary factor in determining the formation of the village.

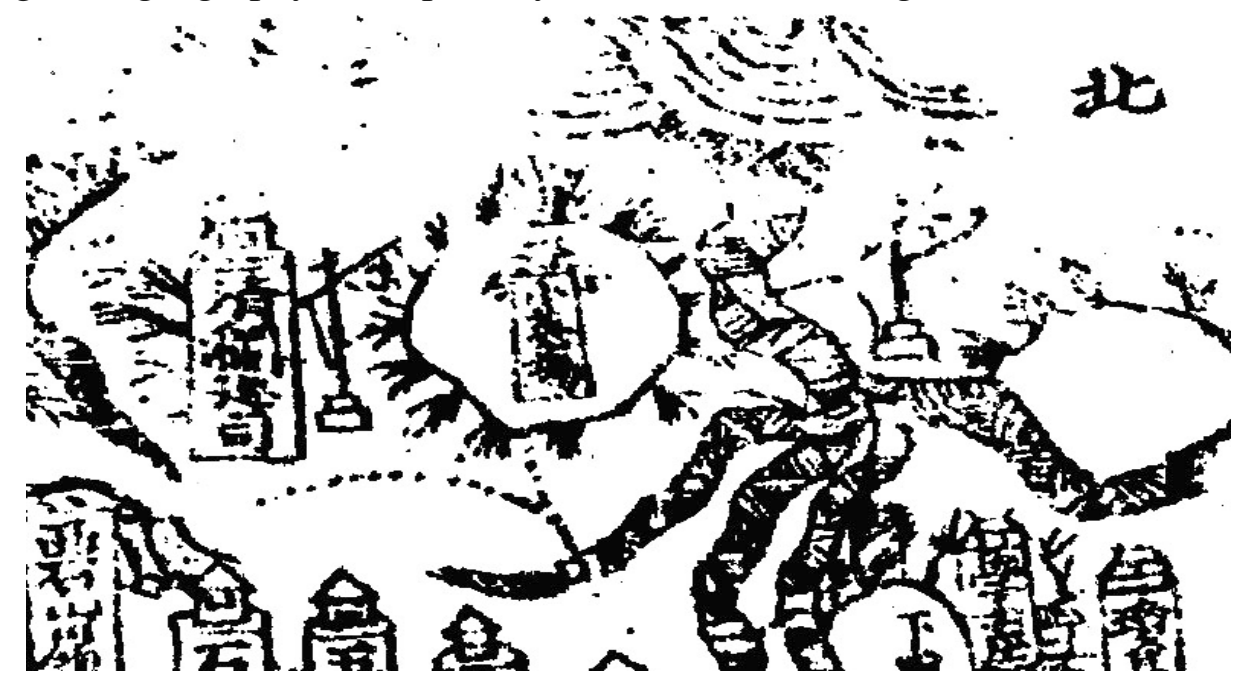

Figure 1 "Zheng Deqiong Taiwan Chi a" Qiongshan County map part ${ }^{[1]}$

"Wanli Qiongzhou Fu Chi" Previous local records of Hainan did not mention Bin Ya village, the history of the village of traceability, only by studying folk genealogy and pedigree records and visits to complete. It is reported that the development of Bin Ya village began in the Yuan Dynasty. According to the family tree of Zhang, which of offered by villager of Bin Ya- Zhang Yun-kun, one of the descendant of Zhang family, it shows that in the year of Zhi yuan fourteen of Yuan Dynasty, official of Jin Yi Lang who named Zhang zhao, the progenitor of Zhang was move in Bin Ya, with his chief of Ping Zhang Ali, because of war, they moved here, they found this new land and made it as their homeland. Although there is no record, but "Zhengde Qiong Tai Chi" in the Tang Dynasty records: "Jinghaiying, in the west of the city. In the time of Zhiyuan, Many Han army settled here." [6] "Yuan Shi" also special emphasis on the yuan government On the management of troops in Hainan, this was a ways to control the policy of this place. Lin Hongmin said: "The main way for the mainland to emigrate to Hainan during the Yuan Dynasty was to reclaim the land. According to" Yuan Shi "records, there were 13,000 people who settled down in Hainan Province to reclaim the land." [7] The development of Bin Ya Village starts at this time.

Benefit from the Yuan Dynasty system of reclaiming the land, Zhang joined in army, immigranted with the military in Haikou, came to Bin Ya Village, open up this piece of land, from that time, the history of Bin Ya Village began. According to "Dao Guang Qiongzhou Fu Chi", Qiongzhou "most of official came from Zhongzhou county, people who lived in the area most are soldiers or their family, came from different places... ... Since Hongwu year, family named Zhang, who firstly moved here were not the same family, they came from many family but had the same family name, most of them were from area of Su and Zhe. And other family like Chen,who settled this area later were mostly came from Hebei and Henan. ...... "[8] This movement of reclaiming the land specially pointed to the policy in Yuan Dynasty, which asked many soldiers who were from different places settled in one unexploited areas to protected the government. As this policy, immigrants settled down in the north coast of Hainan Island. As it refered,"family named Zhang, who firstly moved here were not the same family, they came from many family but had the same family name, most of them were from area of Su and Zhe”, it was said that the Zhang family came from Jiangsu and Zhejiang, family of Zhang who were villagers of Bin Ya had the same view. As their family tree says, their ancestors came from Ningbo, one of the city in Zhejiang. Zhang settled immigrants, thus clearer the pioneering history of this village, is the history of immigrants in the village of Bin Ya. 


\section{The Model: The Development Process from the Blood relationship to neighborhood}

In the Chinese-style farming system, the traditional family system renders people accustomed to life linked by blood. The ancients said: "flesh and blood attached, and human wishes are also." [9]Maurice Friedman, an outstanding representative of the anthropologist of Sinology, came up with an influential concept in his examination of rural China's society - the "Corporate Group"[10], referring to China's southeastern region, clan and The villages overlap prominently so that many villages have only a single clan. In fact, the famous Chinese scholar, Lin Yaohua, once discussed the issue of village clans in his book "Clan Studies of Yixu"[11], which he wrote in the opening essay: "Clan villages are a kind of village. Descendants derived from ancestors, called the clan; the village is a natural combination of geopolitical groups, township is the village from the set of political groups, now the word of 'village', is the meaning of the natural geo-community, the concept of community. "[12] The theoretical inquiry into the issue of the clan in rural China shows the important role of clan elements in the process of rural development. In China, behind the political groups in the countryside are the clan systems linked by blood ties.

The family of Zhang has played a very important role in the historical development of Bin Ya Village. This family is the largest proportion of the population in the village. Currently Bin Ya village residents a total of four surnames: Zhang, Chen, Wang, Li. Zhang's descendants Zhang Dechang introduced like this: thanks to the policy of reclaiming the land in the period of Zhiyuan in Yuan Dynasty, Zhang clan first moved into the reclamation and living in the area; then Chen moved in, Chen were from two groups into this village. The first batch was moved from Qiongshan County (now Qiongshan District, Haikou City) in the early Qing Dynasty, and the second batch was moved from Xiuying Village (Xiaoying Square in the Ming Dynasty, now the seat of Haikou artillery house) in the late Qing Dynasty. Lee moved from Xiuying District in the late Qing Dynasty; Wang was in late Qing Dynasty. An elderly man in Bin Ya village adopted a child whose family name was wang because of having no child. when the child was grown up, that old man told him his family named and buy him another fields in Bin Ya village. So Wang clan entered the village of Bin Ya. Bin Ya village secretary had said that: "At present, Bin Ya village has the area of about 400 acres, the total population of nearly four thousand people, of which 1612 were indigenous villagers, immigrants about two thousand people.Surnamed Zhang is about total population of $70 \%$, surnamed Chen about $27 \%$ of the total population, the remaining population of about $3 \%$ of surnamed Wang and Li."

The immigrant villages are the basic social and political units formed on the basis of kinship tradition. Blood relationship has always played an important role in the development of immigrant villages. Especially in the early stage of immigration, clan activities maintained by kinship became the decisive force for early village construction. However, based on Hainan's unique island geography, under the pressure of survival of the underdeveloped and fiefdated island environment and the existance of the expatriate (native Aboriginal Li nationality), the blood ties in Hainan's immigrant villages are slightly open, and the immigrant villages surrounding the Haikou are usually not limited to A surname, while for a variety of opportunities contributed to several surnames public body. As the data and data showed above, after the village of Bin Ya, Zhang, Chen, Wang and Li Si surnames moved in due to different opportunities to jointly develop the village. Due to the pressure of aliens, the immigrant villages in Haikou are under the pressure of aliens. In order to resist the natural disasters, overwhelmed migrants gradually expand their dependency on the dependents of the villagers. The development course of immigrant villages is the development course from blood relationship to rural neiborhood.

\section{The Cultural Character of Immigrant Villages - Sense of identity}

Immigrants from the outside of the island into the immigrant villages formed by the reclamation of the Hainan island society are a marginal group that is free from the local core groups. There must be conflicts between the marginal groups and the core groups, and it is necessary to run in. In addition, the marginal groups, the regional groups Conflict and conflict between the two sides also 
exist in the newly reclaimed areas of immigrants. Therefore, immigrant groups are faced with the issue of how to gain acceptance and integrate into the local community. Identity is a common emotion and belief. It is a cultural tendency of human beings to embed a cultural system in their psychological structure and human structure and judge life and regulate behavior. Its basic purpose is to define themselves. And cultural identity, "refers to the recognition of the common culture between people or between individuals and groups. Using the same cultural symbols, follows the common cultural concept, adhering to the common mode of thinking and code of conduct, is the basis of cultural identity. Is one of the basic functions of culture. "[12] Generally speaking, such identification should emphasize both the identification of immigrant groups and the indigenous core groups and the self-identification of immigrant groups.

Based on the particularity of the Hainan Island environment, Hainan has experienced shortage of land and resources. Due to its low productivity and cultural backwardness, more problems with the identification of Hainan's immigrant villages are reflected in the groups of immigrants. This cultural identity is mainly reflected in the villages of immigrants in Hainan In two aspects: one is to create a common space of belief in the field of material culture - the temple; and the other is to form a village mass festival in the non-material culture.

\subsection{One of the ways to strengthen the geo-cultural identity is the temple.}

As a collective belief in Bin Ya village space - Hairui temple, were built in the northwest of village. Haikou villages are generally built temples, which is the cultural identity of immigrants in Haikou universal. According to Haikou customs of the village, the village has the village's public worship space - temples, said "gongjiang" (Haikou dialect), or "Temple", for the villagers to worship and dedicated to their gods. Bin Ya village has "Hairui temple" (also known as Hairui Ancestral Hall), the villagers identified the god of their village was "Hairui". However, although it is named Hairui Temple, the temple is dedicated to more than one god, besides the god of Hairui, as well as the god of Banshuai, Guan Gong, Tathagata Buddha, the Great God, the Weixian god, all those gods blessing the people living in this village. Strong cultural identity appeal, the clan factions mixed in a temple.

The villagers came here to worship, did not emphasize the belief, but expressed a common social psychology. The temple was linked to the life of the villagers within a certain spatial scope. Its existence played an important role in strengthening the geo-relation and cultural identity .

\subsection{The other way to strengthen the cultural identity: village festivals.}

As a typical immigrant village, there are three festivals in the history of Bin Ya Village. Bin Ya Villagers "took the day of the Hai Rui burial day as 'Hai Rui traditional culture and festivals day', Every year on the 22nd day of the second lunar month, the grand anniversary of Hai Rui is held...... The official written so-called "Hai Rui traditional culture and festivals" in the folk custom is called "Hai Rui Day"; and "Ban Shuai Day" in folk is another title, known as the "Ban Gong" or "Black Facial God. " So, their were three traditional village festivals in the history of Bin Ya Village: "Given Day" in the lunar lunar January 20 ,and "Hai Gong Day" in Lunar February 20, "Ban Gong Day" in the fourth day of the fifth lunar month.

Village festival presents a rich and complex historical and cultural information. At the time of the festival, the village hold lantern everywhere, play the stage, all villages were entertaining friends at their house. Local festivals with collective carnival meanings encourage villagers to gain a stronger sense of collective identity so as to achieve cultural identity while promoting the integration of villagers.

\section{Viewpoint: The loss of traditional Village}

Anthropologist Clyde Woods argues that "change is an eternal phenomenon in all socio-cultural systems, although the pace of change and the form of expression are very different under different circumstances." [13] Bin Ya village, "one of the fifteen traditional villages of Haikou", which was built in the late Yuan Dynasty, as a typical Haikou immigrant villages, to cater the construction of 
Hainan International Tourism Island, in order to develop the Hai Rui tomb tourist attractions, it was disappearing in the stream of time. In 2012 December, the renovation of the old city of Haikou Bin Ya village was officially launched. This renovation was led by the government, named " the renovation of the old city of Haikou Bin Ya village", it was guided by the government of the Longhua District, Haikou City. The government will be in the overall renovation of Bin Ya Village project invested about 1.4 billion yuan, will be bound to play the village of Bin Ya area to the core area of the Hai Rui tombs as incorrupt culture and show the concept of governing for the people, meanwhile develop its tourism, culture, living, business services, make this palce a full-featured integrated community facilities. Bin Ya Village suffered the first comprehensive history of "state-in-society"[14]. Although government behavior has always existed in the private sector and government acts have indeed caused mortal misfires in the folk culture, Gao Bingzhong once mentioned that "the decades-long experience of folk culture in the People's Republic of China caused a huge break with the social reality, It is very difficult now to bridge this historical gap." [15]However, the relationship between the government and the people in the past 20 years is still relatively modest, and the state is generally present as a symbol and gives the private space for growth. Therefore, to a certain extent, the tradition has gained a new round of recovery among the people. Such traditional recovery is manifested in the complicated cultural space once again. For example, Bin Ya Village, once again enveloped in incense from the beginning of the 80th century "Hai Gong temple", once again has a long history as a unique cultural carrier - Bin Ya Village, the traditional village, in the private real rendering of their own personality and charm.

In promoting the "Intangible Cultural Heritage" project, UNESCO used a key concept of "cultural space". Folklore focuses on the cultural space on which each social system is based. Each individual society relies on the concrete cultural space and runs its own logic of public logic. All these kinds of logic encounter various impacts and changes during the process of their march and are reconstructed by absorbing external factors to form a new logical mixture that leads to the overall culture Reconstruction of space. The reconstruction of cultural space is the inevitable development of society, and if the reconstruction is only led by the people, the continuation of cultural space is sustainable. However, when people encounter the government, the traditional encounter the modern, cultural impact economy, the development of cultural space will face unpredictable development of mystery.

The relationship between the government and the private sector affects the development of folk culture in a certain environment. The transformation of the old city is an extreme expression of the change of the village. This kind of government-led behavior has an extremely strong impact on the private sector and inevitable changes in the village. The village collapses or Nirvana ,that's a question.

At present, Bin Ya Village is a mess, one ruins. Demolition forklifts are still roaring, digging machines in the noise and agitation, what was collapse? it was not only an old pavilions, temples, houses or ancient wood, as well as the folk "cultural space", it was shaken,. When the material culture is reconstructed, the non-material culture of the region must be rewritten accordingly. It is reported that three years later, Bin Ya village villagers expected to stay in the new built by the reinforced concrete apartment. "Hai Rui temple" was demolished, the demolition of the temple will be a scene within the Hai Rui tomb area. "Hai Rui temple" is transformed into a commodity because of its becoming a tourism resource, facing the crisis of losing the meaning of the folk. However, due to the lack of material expression space, the folk festival also loses the "field" of activity and the light shines away. Cultural identity of immigrant villages collapsed, and Bin Ya Village suffered a bottleneck as a traditional village development.

It may be gratifying to gain an understanding from the sociological point of view on the issue of the identity change of villagers. The good news is that the villagers of Bin Ya will be turned into residents by the villagers in the true sense because of the collapse of traditional village ties. This is also a society Progress sign. However, the issue of demolition may be complicated by protecting the village traditional culture and defending the "public culture" space of regional characteristics. This paper believes that the disintegration of traditional culture is bound to make the crisis of cultural 
identity. Under the impetus of modernity, the individuality of immigrant villages will be replaced by universality. However, the cultural identity is actually related to the social development and social stability. Although the villages of traditional significance no longer exist, the activities of residents in the region are still continuing. How to foster new cultural identities is a problem that should be paid attention to in current regional reforms.

\section{Acknowledgements}

Fund Project: This article is one of the scientific research results of 2016 Hainan Province philosophy and social science planning project "Bin Ya Village: Hainan traditional village culture change case study" (HNSK (YB) 16-127)

\section{References}

[1] (Ming) Tang compilation. Peng Jing middle school. Zheng Deqiong Taiwan Chi. Volume twenty. Soldiers defense. Haikou: Hainan Publishing House, 2006: 13.

[2] (Ming) Dai, President Ouyang Chan. (Ming) Cai Guang before compiling. Haikou: Hainan Publishing House, 2003: 57.

[3] (Ming) Dai, President Ouyang Chan. (Ming) Cai Guang before compiling. Haikou: Hainan Publishing House, 2003: 222.

[4] Hong Yuanlong. Haikou City, "Wulong play beads." Coconut City [J]. 2006 (9): 20.

[5] Liang Yuxin. Haikou, the port of entry into the sea. Coconut City [J]. 2007 (7): 13.

[6] (Ming) Tang compilation. Peng Jing middle school. Zheng Deqiong Taiwan Chi. Volume twenty. Soldiers defense. Haikou: Hainan Publishing House, 2006: 339

[7] Lin Hongmin. Hainan Province, population, resources and environment [M]. Haikou: Southern Press, 2008: 13.

[8] (Clear) Ming Yi Xiu, Zhang Yue Song compilation. Haikou: Hainan Publishing House, 2003: 93.

[9] (Han) Ban Gu. Han book. Volume nine. Yuan Di Ji ninth. Beijing Zhonghua Book Company. 1962: 292

[10] Maurice Freedman, Lineage Organization in Southeastern China. London: Athlone, 1958, pp. 126-133

[11] Lin Yaohua. Patriarchal clan research [M]. Beijing: Living • Reading • Shinwoo Joint Bookshop, 2000: 1

[12] Cui Xinjian. Cultural Identity and Its Roots [J]. Journal of Beijing Normal University (Philosophy and Social Science). 2004 (4): 103.

[13] (United States) Clive Woods. Cultural change [M]. Shijiazhuang: Hebei People's Publishing House, 1989: 22

[14] Migdal, Joel S. and Atul Kohli. Introduction: Developing a State-in-Society Perspective [A]. Cambridge University Press, 1994, pp. 1-4

[15] Gao Bingzhong. Folk Culture and Civil Society: Cultural Studies of Chinese Modern History [M]. Beijing: Peking University Press, 2008: 9 